\title{
Microstructure and Mechanical Properties of Pb-4\%Sb Alloy Processed by Equal Channel Angular Pressing
}

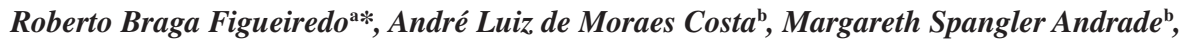
Maria Teresa Paulino Aguilar ${ }^{\mathrm{c}}$ Paulo Roberto Cetlin ${ }^{\mathrm{a}}$

${ }^{a}$ Metallurgical and Materials Engineering Department, Universidade Federal de Minas Gerais, Rua Espírito Santo, 35, Centro, 30160-030 Belo Horizonte - MG, Brazil

${ }^{\mathrm{b}}$ Metallurgical Technology Division, Fundação Centro Tecnológico de Minas Gerais, Av. José Candido da Silveira, 2000, 31170-000 Belo Horizonte - MG, Brazil

'Materials and Civil Construction Department, Universidade Federal de Minas Gerais, Rua Espírito Santo, 35, Centro, 30160-030 Belo Horizonte - MG, Brazil

Received: December 2, 2004; Revised: December 8, 2005

Equal Channel Angular Pressing (ECAP) is the most prominent SPD (Severe Plastic Deformation) method for the production of ultrafine and nanostructured metals, and has been extensively employed and analyzed. This technique was applied to a $\mathrm{Pb}-4 \% \mathrm{Sb}$ alloy at room temperature, in order to study its effect on a low melting point and multiphase metallic material. The material was subjected to effective strains higher than 9 , after 8 passes of processing, where dynamic and static recrystallization are expected during and after each pass. This eliminates any grain refinement and allows the analysis only of the microstructural effects associated with second phase redistribution and eventual precipitate dissolution. ECAP followed route $\mathrm{C}$, which eliminates structural alignment after each even ECAP pass, facilitating the study of the microstructural evolution. It is shown that three ECAP passes are necessary to completely break the lamellar structure of the as cast strucure and that antimony dissolves into the lead rich matrix. Dynamic recrystallization and structural changes reduce the material strength and change the flow curve format.

Keywords: equal channel angular extrusion, $\mathrm{Pb}$-Sb alloy, dynamic recrystallization

\section{Introduction}

Severe plastic deformation (SPD) has been arousing great scientific interest, especially due to its capacity of producing materials which display unusual properties ${ }^{1}$. One of the advantages of some of the SPD methods is the possibility of achieving fabrication rates and costs comparable to those for the production methods of conventional materials, making use of equipments similar to those used in conventional deformation processing ${ }^{2}$.

Equal-Channel Angular Pressing (ECAP) is the most prominent SPD technique, due to its capability of producing bulk workpieces free of porosity and inclusions ${ }^{3}$. There has been also attempts to adapt this technique to continuous processing, enabling the production of materials in a large scale, efficient and cost effective manner ${ }^{4}$.

During ECAP the workpiece is extruded through two intersecting channels with the same cross sections. The angle between the channels is defined as $\Phi^{5}$ as shown in Figure 1. One important advantage of ECAP process is that it can be repeated several times without changing the workpiece dimensions and the applied strain can be increased to any level. ECAP allies severe strains and a simple shear deformation mode that contribute to strong, sometimes unusual effects on properties and structure ${ }^{5}$.

Iwahashi et al. ${ }^{6}$ derived a relationship to calculate the imposed strain, $\varepsilon$, in one cycle of ECAP as a function of the angles $\Phi$ and $\Psi$ (angle of the external curvature of the deformation zone - see Figure 1).

$$
\varepsilon=\frac{1}{\sqrt{3}}\left[2 \cot \left(\frac{\Phi}{2}+\frac{\Psi}{2}\right)+\psi \operatorname{cosec}\left(\frac{\Phi}{2}+\frac{\Psi}{2}\right)\right]
$$

Most common dies used in the process have angle $\Phi$ between $90^{\circ}$ and $120^{\circ}$ and angle $\psi$ between $0^{\circ}$ and $180^{\circ}-\Phi$. In these dies the strain for one ECAP cycle is approximately 1. In order to attain adequate microstructural refinement through SPD, strains higher than 4 are usually required and thus multiple ECAP cycles are performed. One important parameter in the microstructural evolution through multiple processing cycles is the workpiece rotation between repetitive extrusions. The angle of rotation defines the processing route and the most common are: route $\mathrm{A}$, where the workpiece is not rotated between cycles, route B, involving a rotation of $90^{\circ}$ of the sample between successive passes, and route $\mathrm{C}$, where this angle of rotation is $180^{\circ}$. Route $\mathrm{B}$ is the most efficient one for microstructural refinement ${ }^{3}$. It is important to emphasize, in the present situation, that route $\mathrm{C}$ is associated only with a shear reversal at each suceeding pass; this means that for each even-numbered pass, the spatial distortion of the microstructure is eliminated, allowing a comparison with the original, pre-ECAP microstructure.

In SPD processes, metals are intensely strained under high pressure. For the case of materials not undergoing dynamic recrystallization (DRX) during the deformation or static recrystalization (SRX) after the straining, the dislocations introduced into the crystalline lattice are rearranged into cells that evolve to new grains ${ }^{7}$. Such grain refining has been exhaustively studied, and grain sizes as fine as $300 \mathrm{~nm}^{8}$ and $210 \mathrm{~nm}^{9}$ were produced in copper, smaller than $400 \mathrm{~nm}$ in aluminum alloys ${ }^{1,10}$ and as fine as $200 \mathrm{~nm}$ in low carbon steel ${ }^{11,12}$. Ultrafine grain structures were also reported in titanium ${ }^{13}$. SPD also leads to dramatic increases in mechanical strength ${ }^{1,8,9}$ for non-recrystallizing materials, where high strain rate superplastic forming capability was obtained in several non-superplastic alloys ${ }^{14-16}$. Changes in other 


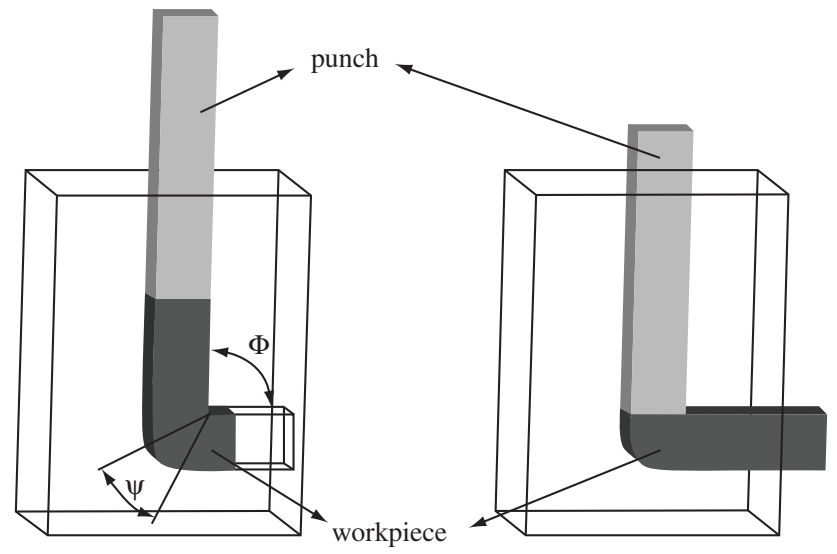

Figure 1. Illustration of the ECAP die geometry.

metal properties such as ultimate solubility ${ }^{10}$, diffusion coefficient ${ }^{17}$ and Young's modulus ${ }^{18}$ were also reported for metals processed by ECAP. For example, in the specific case of an Al-Fe alloy, it has been reported that SPD causes the partial dissolution of the iron rich precipitates in this alloy, with iron re-dissolving into the $\mathrm{Al}$ matrix ${ }^{10}$.

The present paper presents an analysis of the use of ECAP - Route $\mathrm{C}$ to a low melting point, multiphase, as cast $\mathrm{Pb}-4 \% \mathrm{Sb}$ alloy. In the as-cast state, this alloy displays an eutectic, regular structure of a Sb rich phase, which is thoroughly broken by ECAP. Route C in ECAP is associated only with a reversion of shear for every even numbered pass, yielding an undistorted microstructure in relation to the initial, pre-ECAP situation. This allows a comparison of the initial, as cast microstructure, with the microstructures after each even numbered ECAP passes. The $\mathrm{Pb}$ recrystallization temperature is below $0{ }^{\circ} \mathrm{C}^{19}$, and it is expected that the present $\mathrm{Pb}-\mathrm{Sb}$ alloy will undergo dynamic and static recrystallization at room temperature, leading to no grain refinement effects caused by ECAP. One can thus evaluate the effects of the redistribution of the second phase and of the recrystallization of the matrix on the mechanical properties of the as-cast alloy, disconsidering the consequences of grain size changes. Finally, since reports in the literature mention the partial dissolution of precipitates in metals submitted to SPD, probably caused by an enhanced solubility of the matrix ${ }^{10}$, one can investigate the fact for the present $\mathrm{Sb}$ rich precipitates.

\section{Experimental Procedure}

The ECAP die was constructed using ABNT/SAE 1045 quenched and tempered steel. The angle between channels $(\Phi)$ is $90^{\circ}$ and the angle of external curvature $(\psi)$ is $0^{\circ}$. According to Equation 1 the effective strain per pass is 1.15 . The die cross section is square with $16 \mathrm{~mm}$ edge. Figure 2 shows a picture of the die.

$\mathrm{A} \mathrm{Pb}-4 \% \mathrm{Sb}$ alloy was prepared by melting the pure elements and pouring into an aluminum mold. Square section bars were machined into workpieces with dimensions of $16 \times 16 \times 120 \mathrm{~mm}$.

ECAP was carried out at room temperature with $\mathrm{MoS}_{2}$ as lubricant and with punch velocity of $20 \mathrm{~mm} / \mathrm{min}$ in an INSTRON machine model 5582. The samples were rotated about the extrusion axis by $180^{\circ}$ between each pass (route $\mathrm{C}$ ) up to a total of 8 passes. This processing route imparts the smallest end-effects on the samples from multiple ECAP pressings. This effect occurs due to the regions of the billet that do not cross the shear plane during processing and so are not strained as the rest of the billet. The ends of the billets are usually eliminated after pressings to avoid the propagation of end-effects, leading to a decrease of the billet during multiple pressings. However the regions

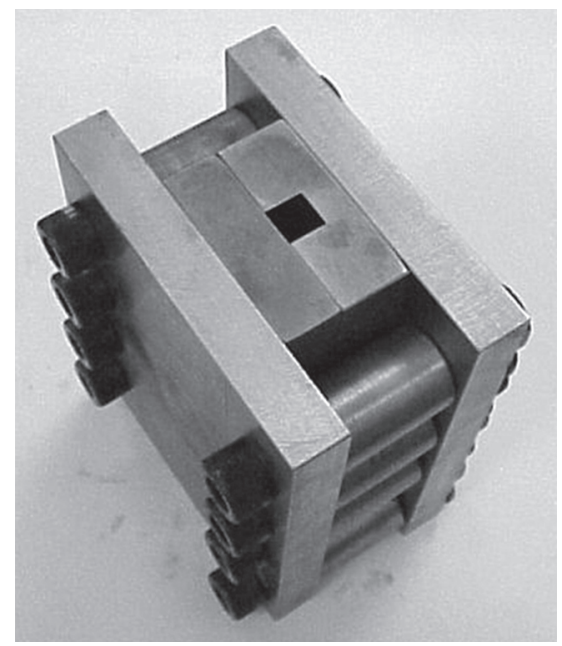

Figure 2. Picture of the ECAP die used.

that do not cross the shear plane are the same during multiple passes with route $\mathrm{C}$ and so the end-effects are restrict to a limited length, and the cutting of the billet edges after pressing is not required.

Samples of as-cast and processed materials were prepared for microstructural analysis by cutting, grinding and polishing with diamond and colloidal silica. Samples of the longitudinal and cross sections were observed. The microstructure was revealed after etching the samples with a solution of acetic acid plus $\mathrm{H}_{2} \mathrm{O}_{2}$. The specimens were observed by Scanning Electron Microscopy at $25 \mathrm{kV}$ using either a JEOL JSM 6360 LV or a JEOL JC XA 733 microscopes. Vickers microhardness tests were performed with a Leitz Wetzlar machine with a load of $5 \mathrm{gf}$.

Cylindrical workpieces for compression tests were machined from the as cast and the ECAP - processed material. They had $10 \mathrm{~mm}$ diameter and $15 \mathrm{~mm}$ height. Compression tests were performed at an INSTRON machine with constant cross head displacement of $1 \mathrm{~mm} / \mathrm{min}$.

\section{Results and Discussion}

Figure 3 a shows the microstructure of the as-cast alloy, displaying a typical dendritic microstructure. The bright phase is the lead rich matrix and the dark phase corresponds to lamelar antimony rich precipitates, formed in the eutectic reaction.

The longitudinal microstructures of the alloy extruded with 1 and 2 passes are presented in Figures $3 b$ and $3 c$, respectively. It is observed that after the first pass the structure attains a preferential orientation at an angle of $27^{\circ}$ with the extrusion direction. As already discussed, the reversed shear associated to successive ECAP passes following route $\mathrm{C}$ eliminates the alignment after each even-numbered pass. This is clearly seen in Figure 3c, which can thus be compared with Figure 3a.

The as-cast structure was well refined after the first pressing, as shown in Figures 4 (cross section of the billet) and 5 (longitudinal section of the billet). The $\mathrm{Pb}$ recrystallization temperature is below $0{ }^{\circ} \mathrm{C}^{19}$, so it is expected that the material recrystallizes during the process and after it. As the grain boundaries do not show the same alignment of the dendrites (see Figure 5) and the same grain structure is observed in the longitudinal and cross section, it is believed that recrystallization occurred after the shear straining.

Figure 6 shows the microstructure of the material after 8 ECAP passes. It was observed that the regions with a higher number of small, broken precipitates commonly display a finer grain size. 


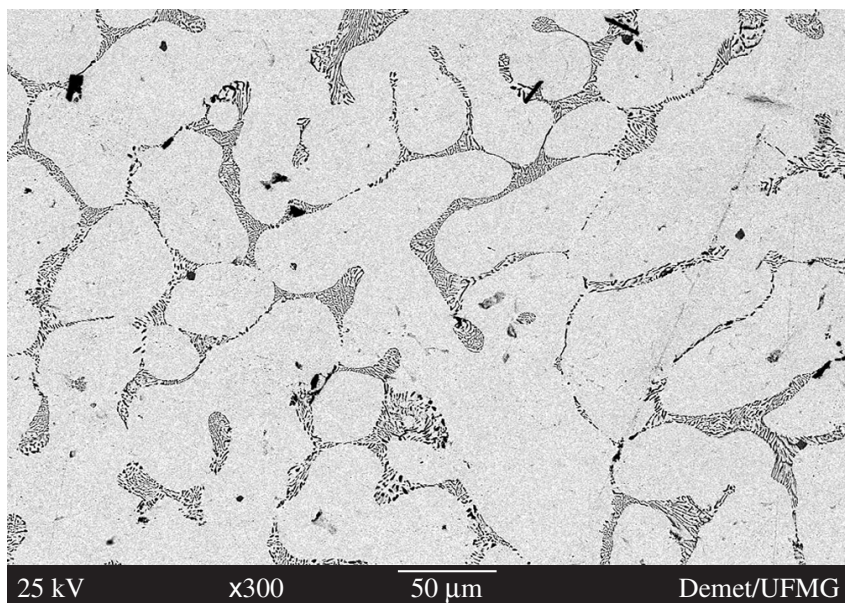

(a)

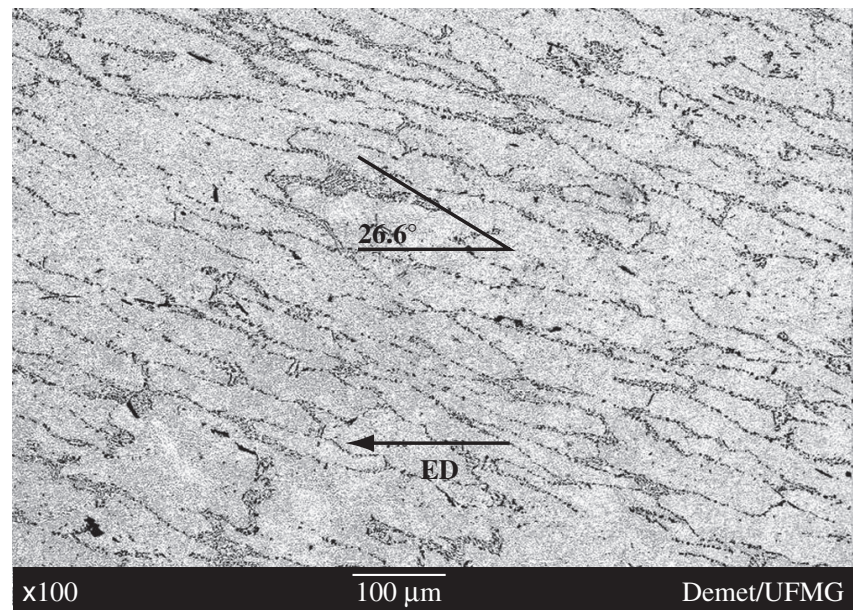

(b)

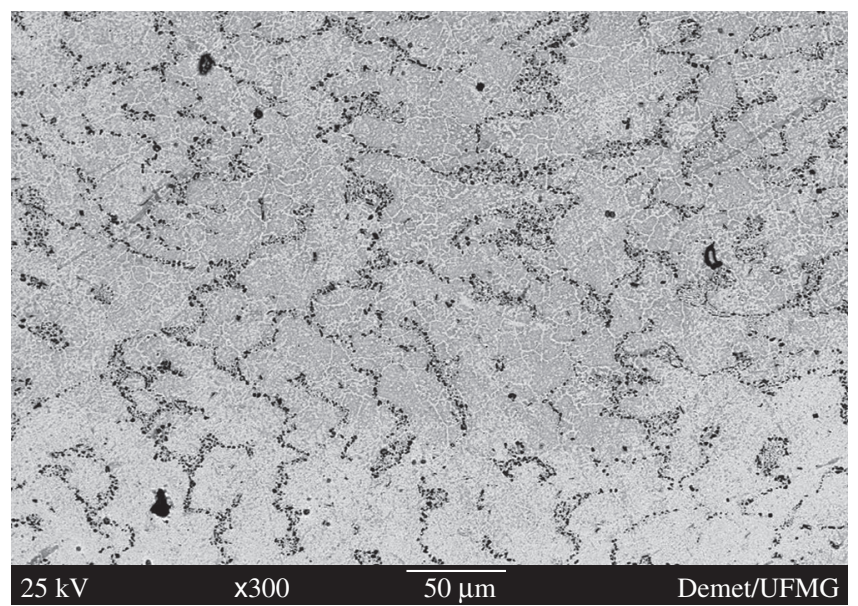

(c)

Figure 3. Microstructure of a) As-cast alloy; b) Longitudinal section of the alloy processed by 1 pass; and c) Longitudinal section of the alloy processed by 2 passes of ECAP.

Figure 7 shows the evolution of the precipitate distribution in the $\mathrm{Pb}-\mathrm{Sb}$ alloy after 1, 2 and 8 ECAP passes. The first pass broke some precipitates, as seen in Figure 7b, but there still remains some larger

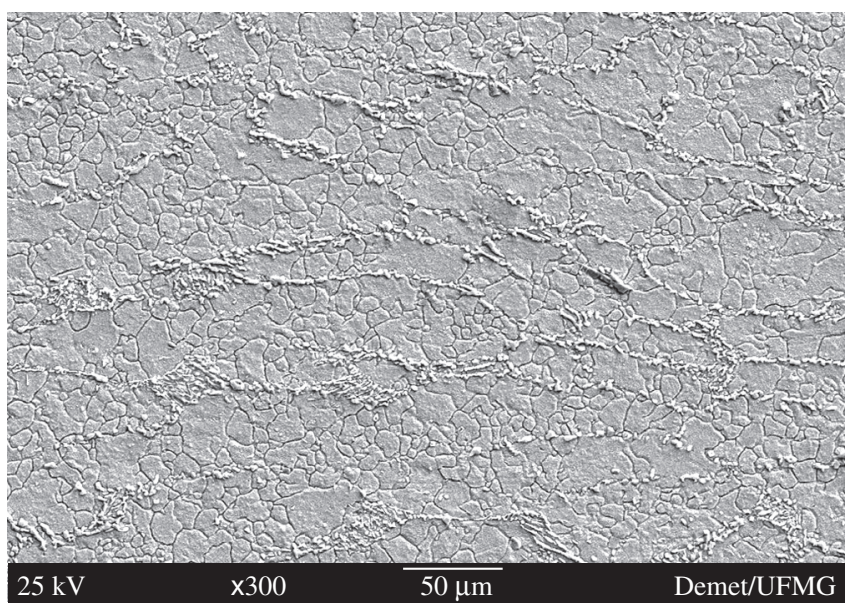

Figure 4. SEM image of $\mathrm{Pb}-4 \% \mathrm{Sb}$ alloy processed by one pass of ECAP (cross section).

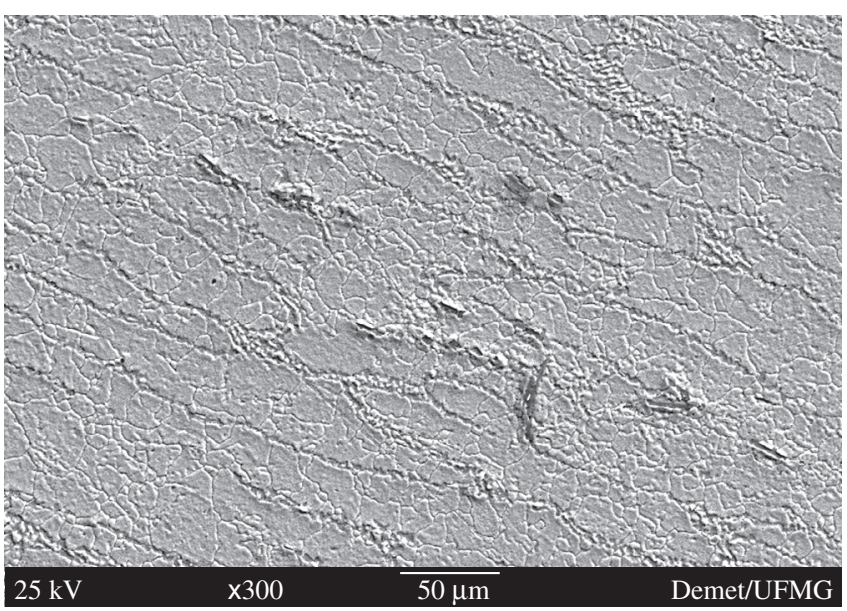

Figure 5. SEM image of $\mathrm{Pb}-4 \% \mathrm{Sb}$ alloy processed by one pass of ECAP (longitudinal section).

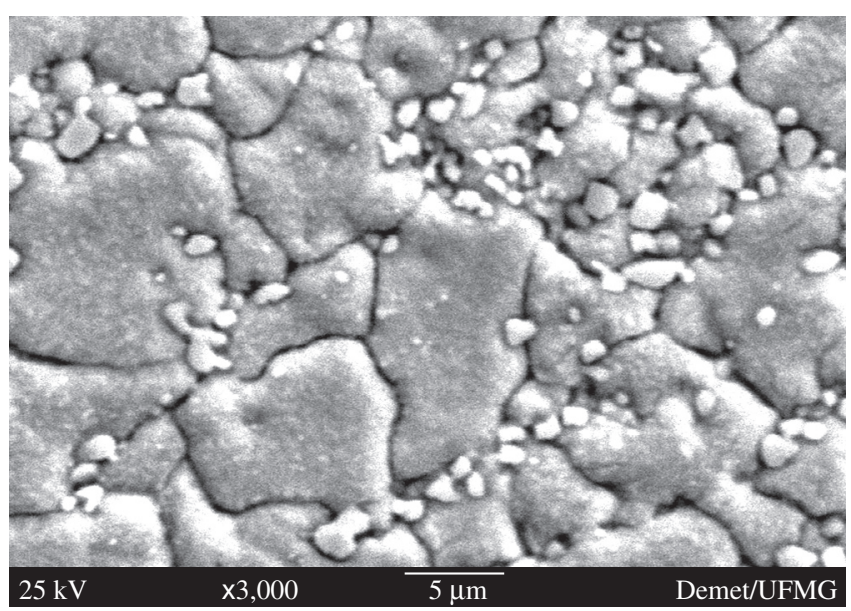

Figure 6. Microstructure of $\mathrm{Pb}-\mathrm{Sb}$ alloy after 8 passes of ECAP.

ones. After the second pass almost all precipitates were broken into small particles (see Figure 7c). Figure 7d shows that further straining seems to reduce the size and the quantity of the particles. It is here important to note that the complete break up of the original as-cast structure seems to occur only after a few ECAP passes. 


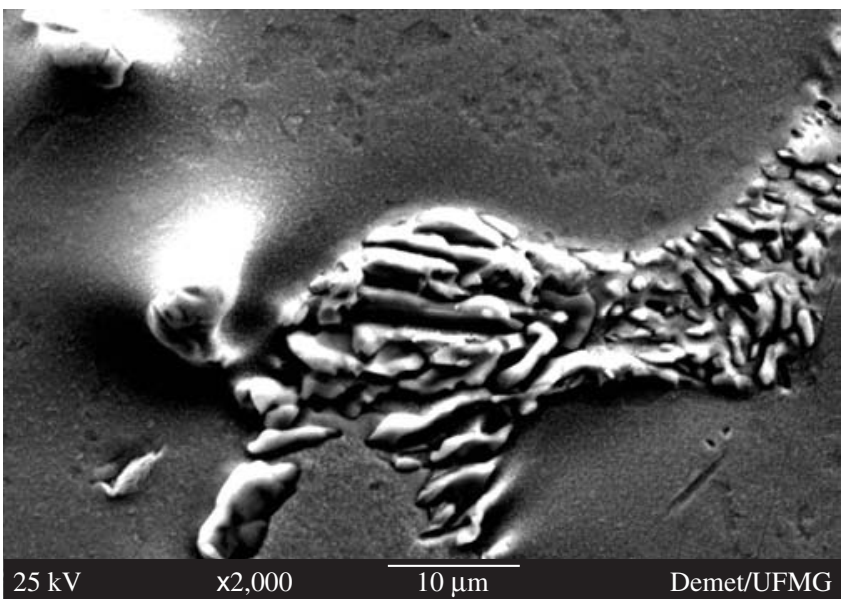

(a)

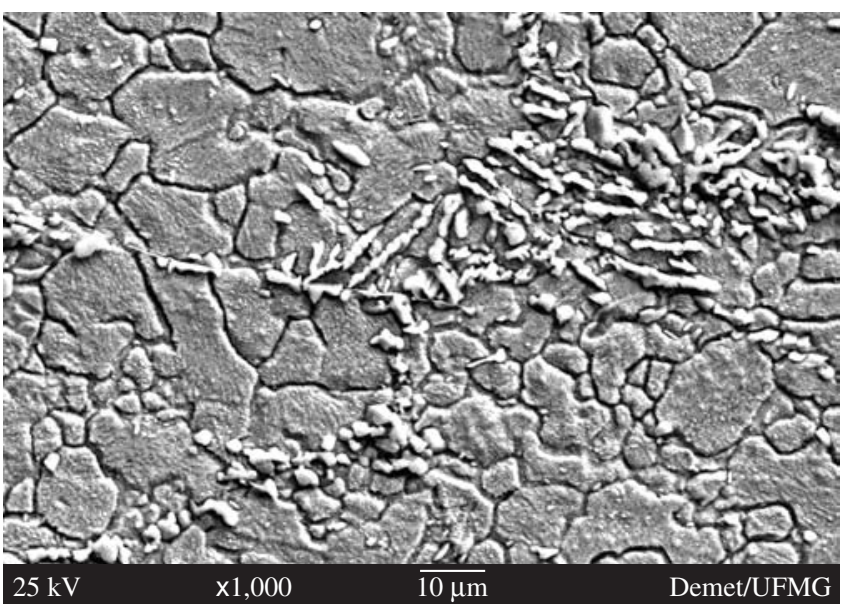

(b)

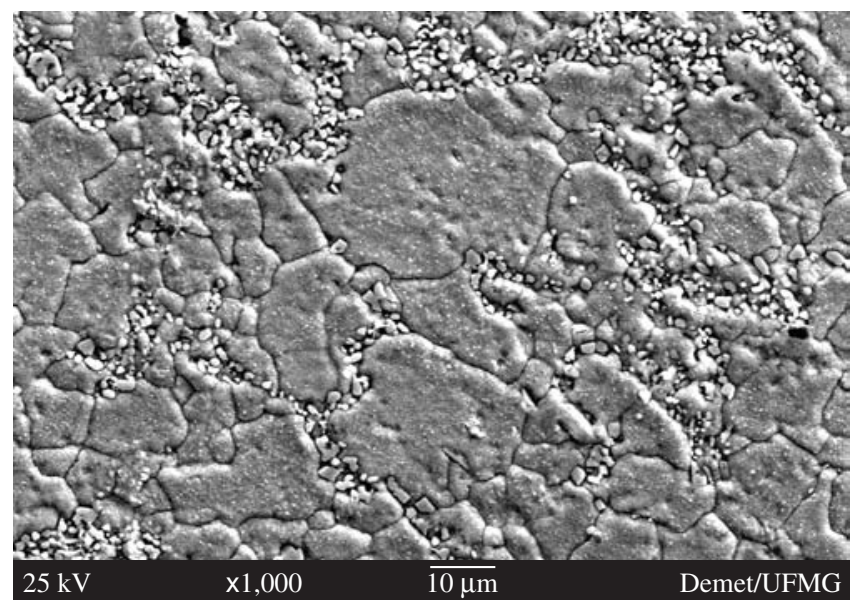

(c)

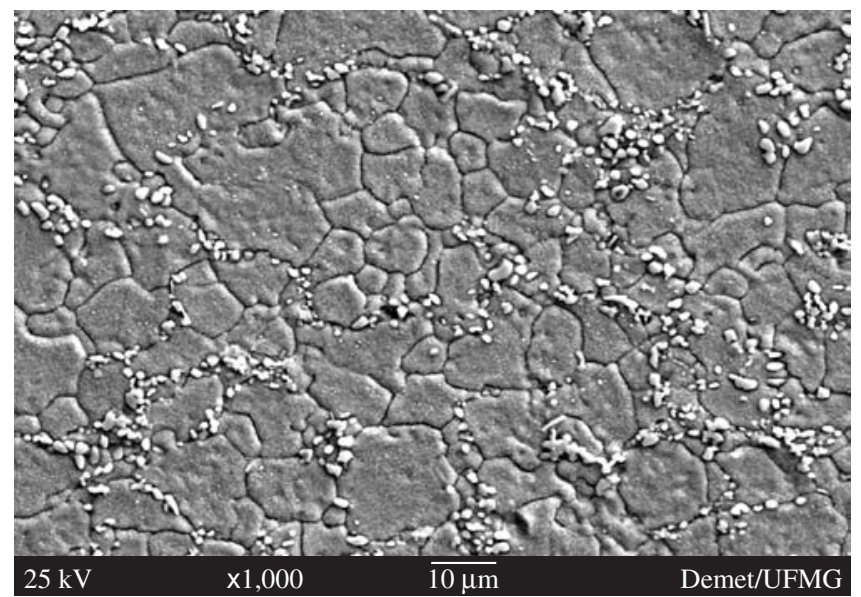

(d)

Figure 7. Antimony precipitates evolution during ECAP: a) As-cast alloy; b) After 1 pass; c) after 2 passes; and d) after 8 passes.

Figure 8a shows the backscattered electron image of the alloy in the as-cast condition, whereas figure $8 \mathrm{~b}$ presents the same image of the material after 2 passes of ECAP. Figure $8 \mathrm{c}$ shows an enlarged view of a typical region in Figure 8b. The darker regions in Figure 8b, which are seen in more detail around the precipitates in Figure 8c, are antimony rich regions, which are not observed in the as-cast structure (Figure 8a). The lighter regions in Figures $8 \mathrm{~b}$ and $8 \mathrm{c}$ correspond to grain boundaries and other topographic effects in the $\mathrm{Pb}$ matrix, caused by etching. This indicates that ECAP caused some dissolution of the antimony rich phase, similarly to the reports in the literature for precipitates in an Al-Fe alloy ${ }^{10}$.

Figure 7 also indicates that the grain size did not change with an increasing number of ECAP passes. This is confirmed through Figure 9, which displays the evolution of the grain size with the number of passes by ECAP. This result was already expected for this alloy, and one concludes that recrystallization occurred after all extrusion passes, similarly to the situation analyzed by Im et al. ${ }^{20}$, that applied ECAP to a $\mathrm{Bi}_{2} \mathrm{Te}_{3}-\mathrm{Sb}_{2} \mathrm{Te}_{3}$ cast. They noted that recrystallization occurred after ECAP and that the recrystallized grains exihibited the same size after all passes.

The material flow curves, determined by compression tests of the material in the as cast condition and after 1 pass of ECAP, are presented in Figure 10. They suggest that dynamic recrystallization occurs during room temperature deformation of the material both in the as cast and after ECAP conditions. There is an initial strain hardening behavior up to a peak stress followed by flow softening and deformation under constant stress. However, the results after ECAP display a considerably lower stress level and a much smaller peak strain, in relation to the as-cast structure $(0.22$ for the former and 0.56 for the latter). This indicates that the microstrucutural changes caused by ECAP, involving the redistribution and break up of the second phase structure, introduces profound changes in the strength and in the recrystallization behavior of the material. The precipitate distribution after ECAP triggers dynamic recrystallization (possibly around these precipitates) more promptly than in the case of the ascast material. At least a part of the softening of the material caused by ECAP is associated with the earlier occurence of DRX in this material, as compared with the as-cast material.

The microhardness of the alloy decreased after the first pass and remained almost unchanged with further passes, as shown in Figure 11a. On the other hand, the expected decrease of the punch force associated with lower microhardness was slower than the fall in the microhardness (see Figure 11b), although the degree of decrease is approximately the same in both cases (about $50 \%$ of the initial value). The punch force reached the minimum value only after the third ECAP pass. The microhardness is connected basically to the local changes in mechanical properties of the material, and the abrupt fall in this property after a single ECAP pass is probably caused by 


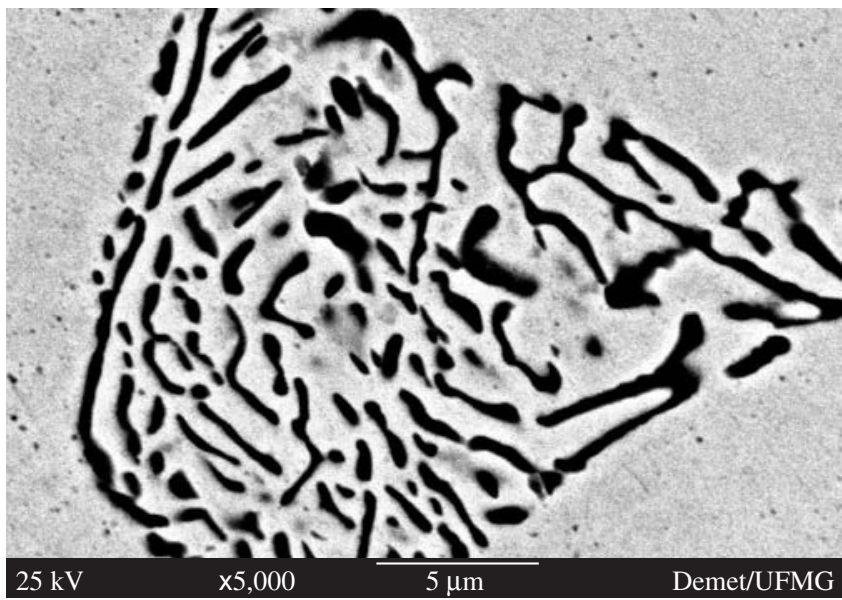

(a) $5000 \mathrm{x}$

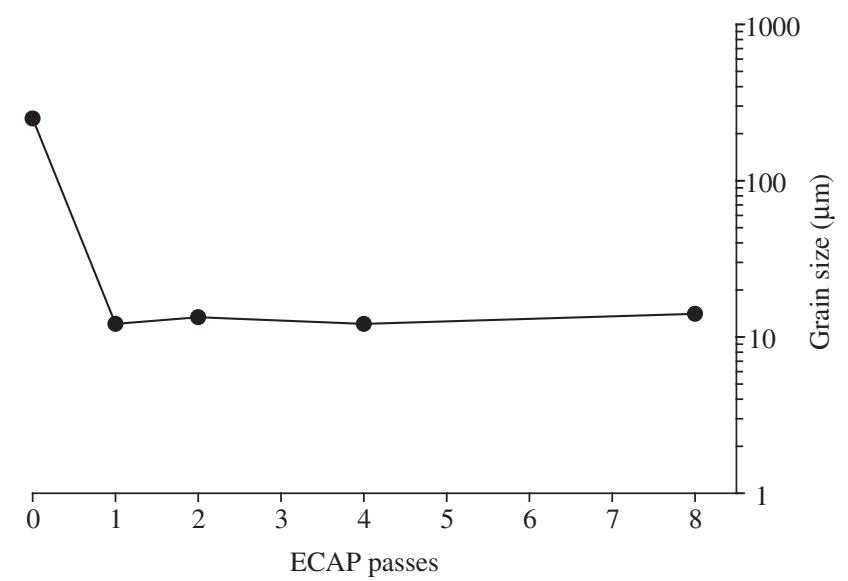

Figure 9. Grain size evolution during ECAP.

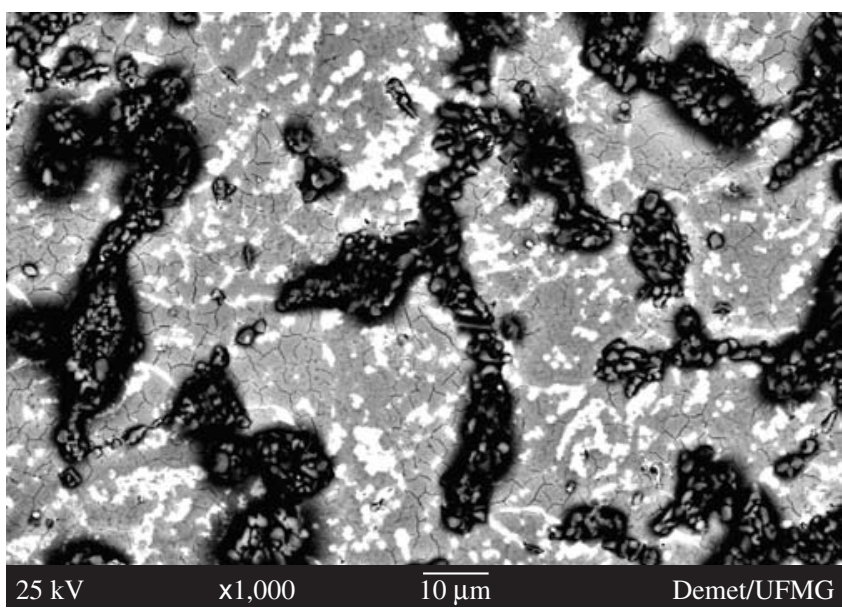

(b) $1000 \mathrm{x}$

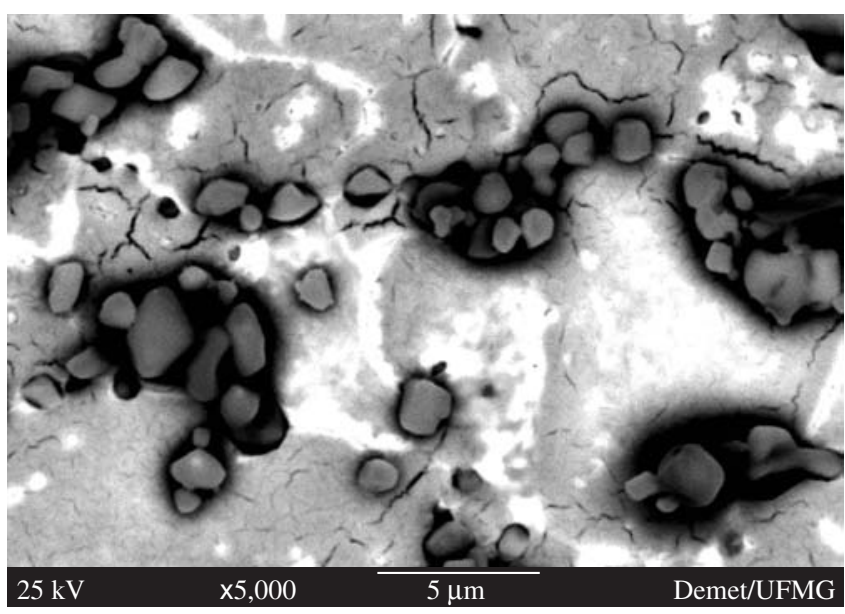

(c) $5000 \mathrm{x}$

Figure 8. Backscattered electrons image of the region around the antimony rich precipitates in a) the as cast state and b), c) after 2 passes of ECAP processing.

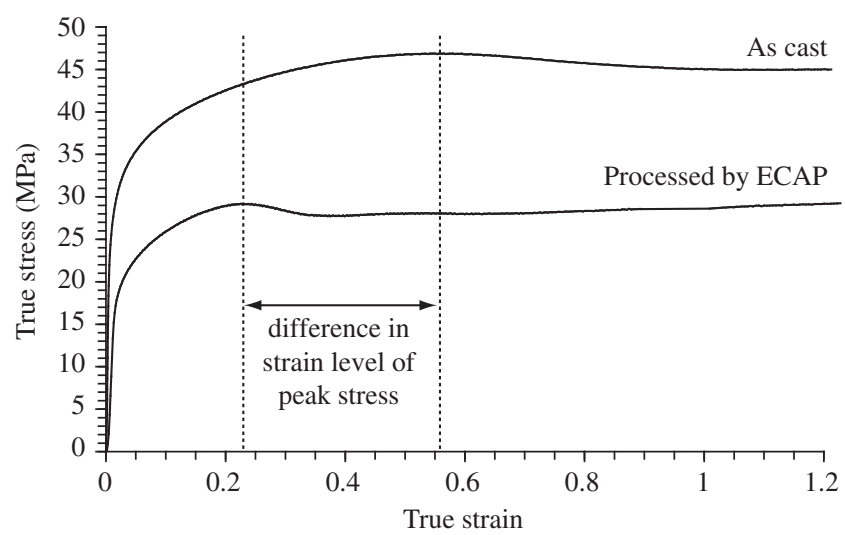

Figure 10. Flow curve of the material in the as cast state and after 1 pass of ECAP, determined by compression tests.

the recrystallization in the material during and after the pass. On the other hand, the punch force reflects not only the local strength changes, but also the overall strengthening effect associated with the second phase distribution in the material, as well as the dynamic recrystallization kinetics of the material. Figure 7 shows that a certain number of ECAP passes is necessary to completely redistribute the second phase structure. This redistribution also accelerated the dynamic recrystallization of the alloy (see Figure 10), probably due to the nucleation of recrystallized regions around the broken second phase particles. Considering the punch force evolution in Figure 11b, one concludes that only after 3 ECAP passes, following route $\mathrm{C}$, does the microstructure of the as-cast alloy stabilize into a situation typical of ECAP processing.

\section{Conclusions}

An as-cast $\mathrm{Pb}-4 \% \mathrm{Sb}$ alloy, processed by Equal Channel Angular Extrusion (ECAP) in up to 8 passes and reaching an accumulated effective strain of 9 , displays a recrystallized matrix of the material after each ECAP pass.

The average grain size of the material is stable, at around $10 \mu \mathrm{m}$, after all the individual passes. Some grain size heterogeneity was 


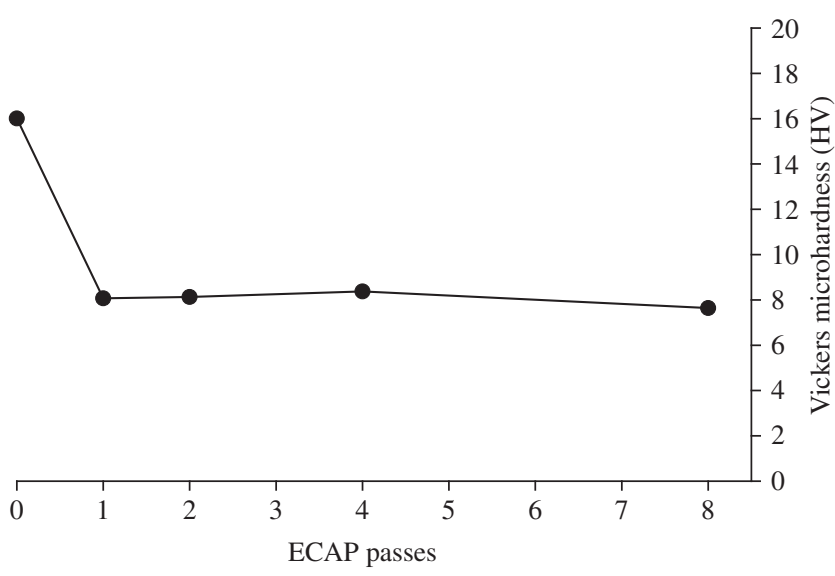

(a)

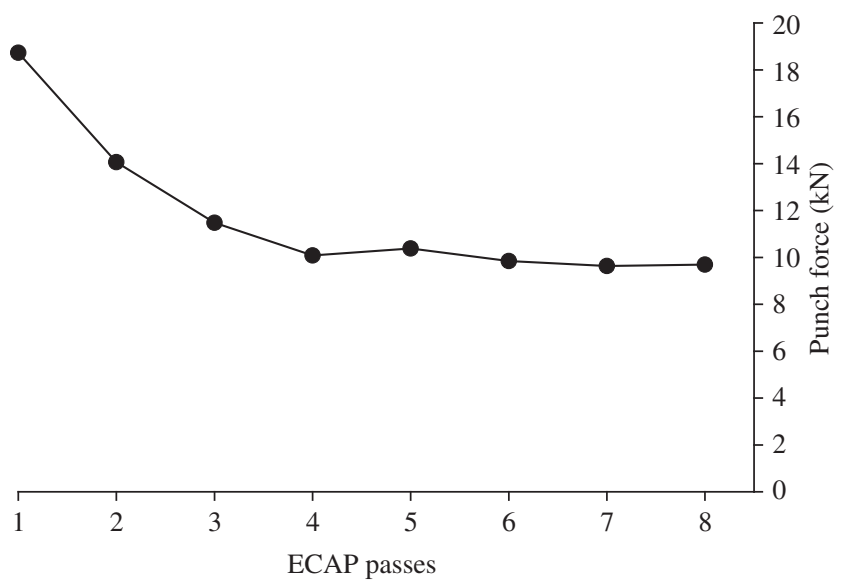

(b)

Figure 11. a) Microhardness; and b) Punch force evolution with the number of ECAP passes.

observed, and finer grains prevail in regions were small, grouped precipitates dominate.

There are indications that the antimony rich precipitates in the as-cast structure undergo some degree of dissolution, caused by the ECAP processing.

The microstructural changes caused by ECAP in the as-cast structure of the material softens the material, due to the break-up of the original precipitate structure and to the acceleration of the dynamic recrystallization of the material, which begins for strains roughly $50 \%$ below that for the as-cast material.

The original microstructure of the as-cast material is broken by the ECAP, but evidence from the required punch force for each pass suggests that at least 3 ECAP passes through route $\mathrm{C}$ are necessary for the complete break-up of the original microstructure.

\section{Acknowledgments}

The authors are grateful for BRASIAÇO Ltda. for the construction of the ECAP die and for CNPq and PRONEX for the financial support.

\section{References}

1. Horita Z, Fujinami T, Nemoto M, Langdon TG. Improvement of mechanical properties of $\mathrm{Al}$ alloys using equal-channel angular pressing. Journal of Materials Processing Technology. 2001; 117(3):288-292.

2. Zhu YT, Lowe TC, Langdon TG. Performance and applications of nanostructured materials produced by severe plastic deformation. Scripta Materialia. 2004; 51(8):825-830.

3. Iwahashi Y, Horita Z, Nemoto M, Langdon TG. The process of grain refinement in equal-channel angular pressing. Acta Materialia. 1998; 46(9):3317-3331.

4. Raab GJ, Valiev RZ, Lowe TC, Zhu YT. Continuous processing of ultrafine grained Al by ECAP-Conform. Materials Science and Engineering. 2004; A382(1-2):30-34.

5. Segal VM. Materials processing by simple shear. Materials Science and Engineering. 1995; A197(2):157-164.

6. Iwahashi Y, Wang J, Horita Z, Nemoto M, Langdon TG. Principle of equal channel angular pressing for the processing of ultra-fine grained materials. Scripta Materialia. 1996; 35(2):143-146.

7. Valiev RZ, Ivanisenko YV, Rauch EF, Baudelet B. Structure and deformation behaviour of Armco iron subjected to severe plastic deformation. Acta Materialia. 1996; 44(12):4705-4712.

8. Wang Y M, Ma E. Three strategies to achieve uniform tensile deformation in a nanostructured metal. Acta Materialia. 2004; 52(6):1699-1709.

9. Valiev RZ, Kozlov EV, Yvanov YF, Lian J, Nazarov AA, Baudelet B. Deformation behavior of ultra-fine-grained copper. Acta Metallurgica et Materialia. 1994; 42(7):2467-2475.

10. Stolyarov VV, Lapovok R, Brodova IG, Thomson PF. Ultrafine grained $\mathrm{Al}-5 \% \mathrm{Fe}$ alloy processed by ECAP with backpressure. Materials Science and Engineering. 2003; A371(1-2):159-167.

11. Fukuda Y, Oh-ishi K, Horita Z, Langdon TG. Processing of a low carbon steel by equal-channel angular pressing. Acta Materialia. 2002; 50(6):1359-1368.

12. Shin DH, Kim BC, Park K-T, Choo WY. Microstructural changes in equal channel angular pressed low carbon steel by static annealing. Acta Materialia. 2000; 48(12):3245-3252.

13. Stolyarov VV, Zhu YT, Alexandrov IV, Lowe TC, Valiev RZ. Influence of ECAP routes on the microstructure and mechanical properties of pure Ti. Materials Science and Engineering. 2001; A299(1-2):59-67.

14. Xu C, Furukawa M, Horita Z, Langdon TG. Severe plastic deformation as a processing tool to develop superplastic metals. Journal of Alloys and Compounds. 2004; 378(1-2):27-34.

15. Komura S, Furukawa M, Horita Z, Nemoto M, Langdon TG. Optimizing the procedure of equal-channel angular pressing for maximum superplasticity. Materials Science and Engineering. 2001; A297(1-2):111-118.

16. Chuvil'deev VN, Nieh TG, Gryasnov MY, Sysoev AN, Kopylov VI. Lowtemperature superplasticity and internal friction in microcrystalline $\mathrm{Mg}$ alloys processed by ECAP. Scripta Materialia. 2004; 50(6):861-865.

17. Fujita T, Horita Z, Langdon TG. Using grain boundary engineering to evaluate the diffusion characteristics in ultrafine-grainded Al-Mg and Al-Zn alloys. Materials Science and Engineering. 2004; A371(1-2):241-250.

18. Valiev RZ, Islamgaliev RK, Alexandrov IV. Bulk nanostructured materials from severe plastic deformation. Progress in Materials Science. 2000; 45(2):103-189.

19. Metals Handbook. Properties and Selection of Metals. $8^{\text {th }}$ ed, ASM international, v. 1, 1961.

20. Im JT, Hartwig KT, Sharp J. Microstructural refinement of cast $\mathrm{Bi}_{2} \mathrm{Te}_{3}$ $\mathrm{Sb}_{2} \mathrm{Te}_{3}$ by equal channel angular extrusion. Acta Materialia. 2004; 52(1):49-55. 